\title{
SOIL SEED BANK OF AN EXOTIC Acacia sp. PLANTATION AND AN ADJACENT TROPICAL HEATH FOREST IN BRUNEI DARUSSALAM
}

\author{
ADRIAN LEE RAHMAN SUHAILI ${ }^{1}$, KUSHAN U. TENNAKOON ${ }^{2}$ and \\ RAHAYU SUKMARIA SUKRI ${ }^{1 *}$ \\ ${ }^{1}$ Enmiranmental and LifeSaiences Programme, Faailty of Säence, Univesiti Bnumi Danussalam \\ Jalan TungkuLink, BE 1410, Brune Danussalam \\ ${ }^{2}$ Enviromental and LifeScienes Progamme, Faalty of Science \\ and Institutefor Biodiversity \& Enviranmental Reerch (IBER), Univesiti Brune Danussalam. \\ Jalan TungkuLink, BE 1410, Bruné Danussalam
}

Received 28 April 2015/ Accepted 18 November 2015

\begin{abstract}
ABST RACT
Acacias are some of the most successful invasive plants in the tropics, causing significant negative impacts on the biodiversity and ecosystem services of invaded habitats. Their successful invasiveness is partly attributed to the ability to accumulate large soil seed banks in the areas that they invade. Seedling emergence and soil seed bank composition were compared under an Acada mangumplantation and an adjacent tropical heath (kerangas) forest in the Andulau Forest Reserve, Brunei Darussalam. Soil samples were collected from ten $20 \times 20 \mathrm{~m}$ plots set up in three contrasting habitats: the Acaciaplantation, the adjacent heath forest and the transition zone in between. Soil samples were subjected to smoke and heat treatments, following seedling emergence which was observed daily over a 12-week period. In a parallel investigation, variations in species richness, seed density and seed viability of the soil seed banks of the ten plots were investigated. Seedling emergence was the highest in the plantation and the lowest in the heath forest plots, respectively. However, no significant differences among treatments and no significant treatment-habitat interactions were detected. Species richness, seed density and seed viability in the plantation plots were significantly lower than those in the transition zone and intact heath forest plots. Acadamangumseeds were not recorded in the heath forest soil seed banks, but were detected in the plantation and transition zone plots. Lower native plant species richness, seed density and viability in the A. mangumplantation could imply higher regeneration potential for the heath forest habitat if severe habitat destruction was to occur in this forest reserve. It is suggested that proper plantation management practices and close monitoring of soil seed banks are the best practices that could be adopted to minimize the gradual spread of invasiveA caciasinto tropical heath forests of Borneo.
\end{abstract}

Keywords: Borneo, invasivealien plants, kerangas, seed extraction, seed viability, smoketreatment

\section{INTRODUCTION}

Invasive plants are a recognized as major threat towards biodiversity globally (D avies \& Sheley 2007; Simberloff 2009; Corlett 2010). The genus Acaia (Fabaceae) is one of the most destructive invasive plants in the tropics, with 23 species listed as top invaders worldwide (Richardson \& Rejmanek 2011). Globally, the introduction of Australian Acacias began in the 1700s for aesthetical uses and production of woody pulp, fuel wood and timber (Carruthers eal. 2011). The

\footnotetext{
* Corresponding author : rahayu.sukri@ ubd.edu.bn
}

negative impacts of Australian A cacias are broad, often resulting in transformations to the biodiversity and services of invaded native ecosystems (Le Maitre \&al. 2011). Particularly in Southeast Asia, adverse impacts of Acada invasion, such as displacement of natives through competition, changes in ecosystem processes and allelopathy, have been reported (O sunkoya $\&$ al. 2005; Ismail \& Matali 2014; Padmanaba \& Corlett2014).

The invasion successes of Acacias are enhanced by their ability to accumulate large soil seed banks (Richardson \& Kluge 2008). Invasive Acacias also alter the biotic resistance of resident 
seed bank communities, promoting their own spread and the secondary spread of other alien species (Richardson \& Kluge 2008; G ioria \& al. 2012). Invasive A cacias reduce species richness, diversity and composition of soil seed banks of invaded ecosystems, thus changing the vertical structure of above-ground vegetation and community composition of the invaded ecosystems (Gioria \& O sborne 2010). Furthermore, Acaaa enriched soil seed banks act as reservoirs that allow for the persistence of invasive behaviour (G ioria etal. 2012). The success of Acacias in the soil seed banks of invaded areas are often bolstered by anthropogenic disturbances, such as forest fires, which alter environmental conditions of temperature, light intensity and humidity in favour of germination of these exotics (Richardson \& Kluge 2008; Le Maitre etal. 2011).

Australian Acacias (Acada mangum Willd., Acada anainnata F. Muell. and Acada aunialifomis Benth.) were introduced to Brunei D arussalam in the 1990s to be used in timber plantations and as roadside plantings (O sunkoya \& al. 2005). In the twenty years following this initial introduction, A. mangumand $\mathrm{A}$. aunauliformisare now regarded as invasive in Brunei D arussalam (Osunkoya $\notin \mathrm{al}$. 2005). Their spread appears to be most intense along roadside embankments and in disturbed heath (kerangas) forests along fire-prone coastal areas (O sunkoya $\&$ al. 2005), where Acada trees create almost monospecific habitats. In addition to invading these coastal heath forests, Acacias also appear to invade further inland in Brunei, particularly from roadsides and the original plantations into neighbouring natural habitats.

Tropical kerangas forests account for less than $1 \%$ of all forests in Brunei Darussalam and are rapidly under threat from development (Wong \& Kamariah 1999; D in \&al. 2015; Wong \&al. 2015). Plants in heath forests are well adapted to nutrient deficiencies caused by dry, nutrient-poor, acidic soils (Proctor 1999; Fujii 2014). Kerangas soils in Brunei Darussalam are relatively low in nutrient levels, especially low nitrogen concentrations and low pH (Moran \&al. 2000; Metali \&al. 2015). D ue to its ability to fix atmospheric nitrogen, Acada effectively outcompetes native heath forest species in this nutrient-poor environment (O sunkoya \&al. 2005). As such, the invasions of A cacias are a threat to these rare and vulnerable tropical ecosystems in Borneo.
A first step towards testing invasion severity is to determine whether the invasive species impact negatively upon native species in its introduced habitat (Vilà \&al. 2011). Knowledge on soil seed bank dynamics can, therefore, help predict possible habitats susceptible to invasion according to specific attributes of invasive species (Cordell eal. 2002). The specific objective of this preliminary study was to investigate the negative impacts of invasive Acacias by exploring the soil seed bank composition and seedling emergence patterns of an Acada plantation and a neighbouring heath forest in the Andulau Forest Reserve (Andulau FR), Brunei D arussalam. The effects of different treatments with fire-related cues on seedling emergence and germination from the soil seed banks of the plantation and heath forest were also investigated. Three hypotheses were proposed:

1. Acada seed density and viability is the highest in the soil seed bank of the Acada plantation and the lowest within the soil seed bank of the neighbouring heath forest;

2. In the seedling emergence study, seedling diversity of native species is the highest within soils from the heath forest and the lowest in the Acadaplantation soils;

3. Germination of Acada seeds is higher in response to fire-related cues (smoke and heat treatments) when compared to native heath forest species.

\section{MATERIALS AND METHODS}

\section{Study Sites and Soil Sampling}

The study was conducted in an A. mangum plantation and an adjacent heath forest in the Belait D istrict of Brunei D arussalam $\left(4.4167^{\circ} \mathrm{N}\right.$, $114.5833^{\circ} \mathrm{E}$ ). The plantation, covering a total area of $1 \mathrm{~km}^{2}$, is located in an intact heath (kerangas) forest within Compartment 8 of the Andulau Forest Reserve (FR). It was established by the Brunei Forestry D epartment in the early 1990s as a commercial plantation for timber and harvested in 2010 for manufactured wood products (Joffre Ali Ahmad, Brunei Forestry D epartment, personal communications). Since this harvest, the plantation has not been actively managed and A. mangumsaplings are now seen to regenerate naturally. The adjacent heath forest is 


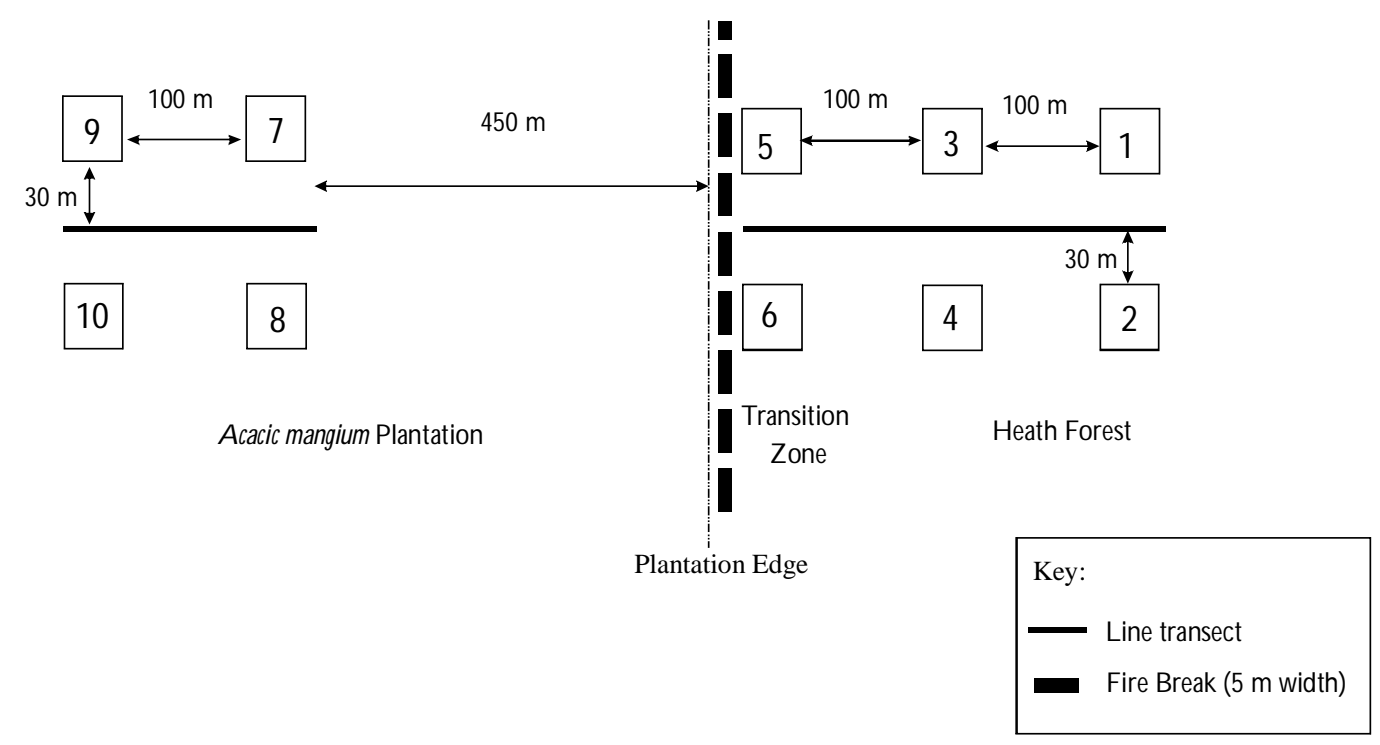

Figure 1 Schematic diagram illustrating the placement of the plots in relation to the Acaia mangumplantation and the Andulau Forest Reserve: four plots were established in the heath forest (HF; Plots 1-4); two plots in the transition zone between the plantation and the adjoining heath forest (TZ; Plots 5-6); and four plots in the A caaaplantation (P; Plots 7-10). D istances between plots in each habitat were $100 \mathrm{~m}$. Each plot was 20 by $20 \mathrm{~m}$ in size

also located within Compartment 8 of the Andulau FR and is separated from the Acaia plantation by a $5 \mathrm{~m}$ firebreak. This firebreak comprised of layers of sand and gravel with ditches on either side of it, allowing drainage.

A single transect line was established from the Acada plantation into the adjacent intact heath forest in a North to South direction. Along this line, a total of ten $20 \times 20 \mathrm{~m}$ plots were set up (Fig. 1): (1) four plots were established in the heath forest (HF; Plots 1-4); (2) two plots along the transition zone between the plantation and the adjoining heath forest (TZ; Plots 5-6) and (3) four plots in the abandoned Acadaplantation (P; Plots 7-10). Plots within each habitat were located at $100 \mathrm{~m}$ from each other. Within each plot, soils at five random points were sampled to a depth of 15 $\mathrm{cm}$ and bulked per plot for seedling emergence treatments. At three other random points in each plot, soils were separately sampled to $5 \mathrm{~cm}$ depth and bulked for the seed extraction study.

\section{Seedling E mergence}

For the seedling emergence experiment, soil samples were subjected to heat and smoke treatments. For the heat treatment, soil samples $(\mathrm{n}=$ 2 replicates per plot) were placed in an oven at $80{ }^{\circ} \mathrm{C}$ for 10 minutes (Hanley \& Fenner 1998; Read \& al. 2000). To conduct smoke treatment, methods outlined by Dixon $\notin \mathrm{al}$. (1995) and Read ed. (2000) were modified as follows: soil samples ( $n=2$ replicates per plot) were placed in a smoke tent and exposed to smoke generated from the combustion of fresh leaf litter collected from the HF plots. Soil samples were then allowed to saturate with smokefor 90 minutes at $40^{\circ} \mathrm{C}$.

Heat- or smoke-treated soil samples from each plot were separated into $500 \mathrm{~g}$ sub-samples and evenly spread out over sterilized potting mixture in $30 \mathrm{~cm}$ by $25 \mathrm{~cm}$ seedling trays (Price tal. 2010). The potting mixture was first sterilized by autoclaving at $121{ }^{\circ} \mathrm{C}$ and $15 \mathrm{psi}$ for 20 minutes (Darbar \& Lakzian 2007). Control trays containing only sterilized potting mixtures, but without any added soil samples were maintained for the duration of the experiment to monitor for contaminations during the observation period.

All seedling trays $(n=60)$ from the three treatments were subsequently placed in a closed plant house at Universiti Brunei Darussalam (UBD) and watered daily. Mean of minimum and maximum temperatures recorded within the plant house were $26.5 \pm 0.4{ }^{\circ} \mathrm{C}$ and $31.6 \pm 0.3{ }^{\circ} \mathrm{C}$, respectively, mean relative humidity of the plant house was $83.3 \pm 1.8 \%$ and mean of photosynthetically active radiation (PAR) was 449.1 umol photons $/ \mathrm{m}^{2} / \mathrm{s}$.

Seedling emergence, expressed as the number of germinating seedlings, was recorded for each tray over a period of two weeks. All emerging 
seedlings were identified using leaf morphological characters (de Vogel 1980; Ng 1991). Unidentified seedlings were transferred to separate pots to allow them to grow further for eventual identification using herbarium facilities. Once seedling emergence had slowed or stopped, soils in the seedling trays were disturbed by stirring with a small spade to mix soil and further encourage the growth of remaining seeds (Price $\&$ al. 2010). Monitoring of seedling emergence in the treatment and control trays was completed after 12 weeks, at which point no seedling germination had been observed in any of the seedling trays for 2 consecutive weeks.

\section{Seed Density and Viability}

To determine seed density in the seed bank, seed extraction methods described by Ball and Miller (1989) and Price eal. (2010) were followed. Subsamples of $100 \mathrm{~g}$ of soil were subjected to floatation, so that seeds could be extracted using a solution of $10 \mathrm{~g}$ sodium hexametaphosphate, $5 \mathrm{~g}$ sodium bicarbonate and $25 \mathrm{~g}$ magnesium sulphate diluted in $200 \mathrm{~mL}$ of water. This solution facilitated the density separation of seeds and organic matter from the soil mineral fraction. O rganic matter and seed fractions that remained after separation were washed with water through $150 \mu \mathrm{m}$ and $75 \mu \mathrm{m}$ sieves, respectively to remove remaining soil and debris. Organic matter and seed fractions were oven-dried at $60^{\circ} \mathrm{C}$ overnight and dried samples were placed in envelopes for storage until they were sorted and counted. Seed sorting and counting was performed using a $10 \mathrm{x}$ magnification dissecting microscope (Meiji Techno Co LTD, Japan). A. mangumseeds were identified by cross checking the morphology with positively identified seeds collected from a fruiting A. mangumtree. Seed density was quantified as the total number of seeds extracted from the soil sample.

Seed viability was determined using the forceps method (Ball \& Miller 1989; Price \& al. 2010), whereby a pair of forceps was used to apply a gentle pressure onto the seed. If the seed resisted this pressure, it was considered as viable, however, if the seed did not resist this pressure then it was considered as non-viable. Seed viability was quantified as the mean number of viable seeds identified from the soil sample.

\section{Data Analysis}

Statistical analysis was done using $R$ version 3.0.2 (R Core Team 2013). O ne-way ANOVA was used to determine differences between plots in heath forest (HF), transition zone (TZ) and plantation (P) for the following parameters: mean seedling emergence, mean species richness, mean seed density and mean viability of the seeds extracted. Assumptions of heterogeneity of variances and normality were not violated. Significant differences detected from one-way ANOVA were further analysed using Tukey's HSD test.

\section{RESULTS AND DISCUSSION}

\section{Variation of Seedling Emergence in Acacia- presentand Acacia-absent Habitats}

O ver the 12-week period, a total of 118 seedlings emerged. Seedling emergence was observed in all plots, except for HF plots 1 and 4. $O$ verall, seedlings emerged at a much quicker rate for heat-treated soils compared to untreated and smoke-treated soils. The P plots had the highest mean seedling emergence (0.613), while the HF plots had the lowest mean seedling emergence (0.030) over the 12 week period (Fig. 2). The oneway ANOVA indicated that seedling emergence showed significant differences between habitats $(\mathrm{F}=14.93, \mathrm{p}<0.001)$, and was significantly the highest in the P plots compared to the HF $(p<$ 0.001) and TZ plots ( $p<0.001$ ). Seedling emergence did not differ significantly between HF and TZ plots ( $p>0.05$; Fig. 2).

The significantly higher seedling emergence in the P plots compared to the TZ and HF plots was possibly due to the higher proportion of $A$. mangumseeds, as well as seeds of pioneer species, such as grasses, that were recorded from the seed banks of the P plots. Seeds of pioneers are better adapted for disturbance and harsh environmental conditions such as high light availability and relatively high temperatures (Swaine \& Whitmore 1988; Khurana \& Singh 2006), therefore, germinate faster in the open microhabitat conditions of theabandoned Acadaplantation. In contrast, seedlings of non-pioneer trees which are more abundant in the heath forest sites, for 


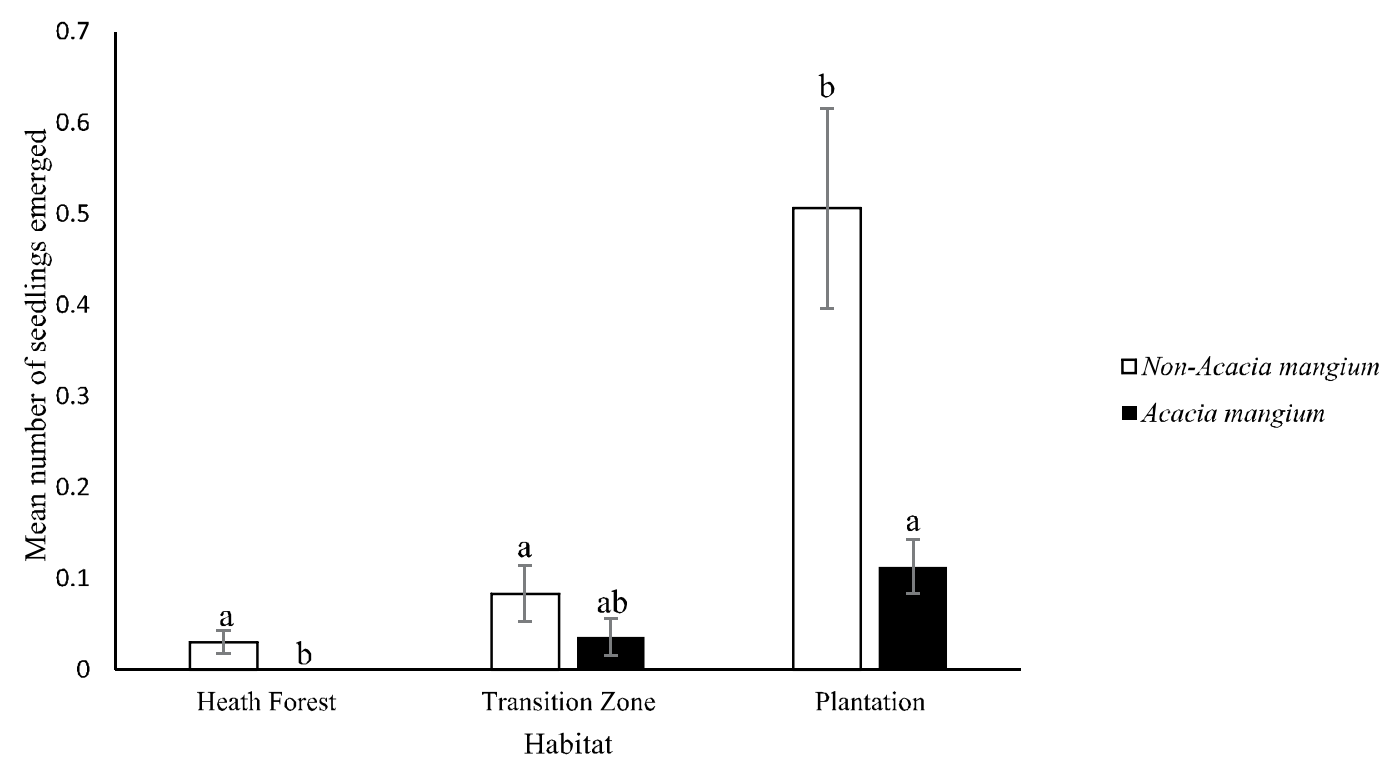

Figure 2 D ifferences in the mean number $( \pm \mathrm{SE})$ of emerging seedlings among three different habitats: Heath Forest (HF), Transition Zone (TZ) and Plantation (P). Different letters above the bars indicated a significant difference (at $\alpha=0.05$ ) in the mean number of seedlings among the three habitats compared

example Agotistadys longfdia, Madura antisii, Syzygim caudatilinbum and Gymostam ndaile (Maidin eal, unpublished data), germinate slower as they are generally less tolerant to high irradiance and temperature (Swaine \& Whitmore 1988; Khurana \& Singh 2006).

A total of 11 different seedlings species were recorded during the seedling emergence study, but the only species that could be positively identified was A. mangum The remaining 10 species were monocotyledons ( $\mathrm{n}=4$ species) and dicotyledons ( $\mathrm{n}=6$ species). All of the monocotyledons recorded were identified as grasses. A. mangum seedlings were recorded emerging from soil samples collected in TZ and P plots, but were not recorded from samples from $\mathrm{HF}$ plots. The $\mathrm{P}$ plots had the highest mean number of $\mathrm{A}$. mangum seedling emergence (0.110) as compared to the TZ plots (0.036). The mean number of $\mathrm{A}$. mangum seedlings emerged were significantly higher in the $\mathrm{P}$ plots than the HF plots $(\mathrm{F}=8.293, \mathrm{p}<0.001)$, but were not different between HF and TZ plots or between TZ and P plots $(\mathrm{F}=8.293, \mathrm{p}>0.05)$.

The significantly lower diversity of native seedlings recorded emerging from the soil seed banks of the P plots is consistent with findings on tree species diversity conducted by Maidin e $\mathrm{al}$. (unpublished data) using the same plots in our study, where the lowest tree diversity was recorded in the A. mangumplantation, with most of the trees comprising tropical pioneer species such as Fagraea splendens Macaranga conifera and Macaranca gigantea, in addition to A. mangum Seed bank composition is highly influenced by the diversity and composition of above-ground vegetation (Dalling \& Denslow 1998), therefore, the lower tree diversity in the $\mathrm{P}$ plots appeared to have resulted in similarly lower diversity in their seed banks. Additionally, the absence of late successional tropical species in the Acaaa plantations plots may also likely be due to the absence of specific environmental triggers, such as suitable temperature, light intensity and moisture levels, that are required for seed germination of such species in the P plots (Baskin \& Baskin 2014).

We had hypothesized that Acacia seeds would be recorded in the HF plots, albeit in lower densities. This is because of the close proximity of the Acada plantation to the HF plots (separated from each other by less than $1 \mathrm{~km}$ ), which had been expected to generate high propagule pressure (Lockwood \& al. 2005; Colautti \& al. 2006) that would facilitate Acaia invasion into the intact heath forest. In contrast, results of this study revealed the absence of A cacias in the soil seed banks of the HF plots. It was suggested that despite the potentially high 
propagule pressure, the spread of A. manguminto the HF plots may be affected by the lack of suitable dispersers. A. mangumis known to be bird-dispersed (Gibson $\notin$ al. 2011), which should allow for seed dispersal over long distances. It is possible that A. nangumseeds from the plantation were not adequately dispersed into the intact heath forests, perhaps because the birds that feed on Acadaseeds do not venture into intact forests. However, it was difficult to ascertain this as further studies are needed to assess bird dispersal of A. mangumseeds from the plantation into the nearby heath forest.

There was a lack of significant treatment effect on seedling emergence, although it had been expected that germination of A. mangum seeds would be especially stimulated by heat and/ or smoke treatments (Portlock \& al. 1990; Willis \& Read 2002; Kulkarni \&al. 2007). It was argued that our results likely indicated that the heat and smoke treatments employed in this study were insufficient to break dormancy and stimulate seed germination, and that further investigations using different heat and/ or smoke treatments may result in a significant treatment effect. In this study, mean temperatures during the smoke treatment remained at $\pm 40{ }^{\circ} \mathrm{C}$ and soil samples were exposed to smoke treatment for only 90 minutes. No reports are currently available on the optimum environmental manipulations required to enhance A. mangumseed germination in the tropics. However, Auld (1986) reported that exposure to high temperatures (between 60$80^{\circ} \mathrm{C}$ ) over any duration, or to extremely high temperatures (between $80-100{ }^{\circ} \mathrm{C}$ ) for durations up to 1 hour, was needed to break seed dormancy in Acada suavedens These temperatures vary greatly between different Acada species depending on their respective degrees of heat tolerance (Auld 1986; Wahid \& al. 2007). Smoke and heat are complementary in stimulating seedling emergence from soil seed banks (Read \& al. 2000; Zuloaga-Aguilar \&al. 2011), and studies have found that Acada seeds typically require smoke and/or heat as cues for germination (Kulkarni \&al. 2007; Zuloaga-A guilar \& al. 2011; Rawson \&al. 2013).

A complicating factor in this study was inhibition of seedling emergence by fungal growth, which was observed in some of our heath forest soil samples. Fungi are ubiquitous in soil and may increase seed mortality thus inhibiting seed germination (Crist \& Friese 1993; Wagner \& Mitschunas 2008). The presence of fungi in heat and smoke treated soils from the heath forest may indicate that these soils were subjected to very little temperature flux that could have otherwise eliminated soil fungal spores (Neary \& al. 1999; Barcenas-Moreno \&al. 2009).

\section{Soil Seed Bank Composition}

A total of 31 different seed types were collected from the ten plots sampled, of which only A. mangium seeds were successfully identified. A. mangumseeds were present in soil samples from TZ and P plots, but absent in the HF soil samples. HF plots registered the highest mean seed species richness, while $P$ plots had the lowest (11.20 vs. 3.50, $F=41.81$, $p<0.001$; Fig. 3). There was no significant difference $(F=41.81$, $p>0.05$ ) between TZ and P plots in terms of species richness.

Comparable observations have been reported by Wang \&al. (2009) where species richness in soil seed banks of established exotic A. mangumand Eucalyptusexsetaplantations in South China were lower than those of the adjacent natural forest habitats. Studies on Acadasaligna invaded areas of the South African fynbos (natural shrubland or heathland vegetation) have also revealed reduced native seed bank richness when compared to adjacent natural forest habitats (Holmes \& Cowling 1997; Gioria \& al. 2014). Low species richness in the soil seed bank of a plantation directly reflects the relatively low species richness in the standing vegetation of a plantation itself (Wang $\notin$ al. 2009). Plantations typically comprise of monocultures with one dominant species being planted over a large area (Evans \& Turnbull 2004), and this same pattern was evident in the Andulau A. mangum plantation in this study. Maidin \&al. (unpublished data) has clearly shown that native heath tree species richness in the standing vegetation of the same A. mangum plantation plots were significantly lower than plots located in the heath forest. O ur observations, therefore, concurred with the hypothesis proposed by Holmes and Cowling (1997), where species richness of both the standing vegetation and seed banks tend to decrease with increasing duration of invasion by exotic species such as Acada. 


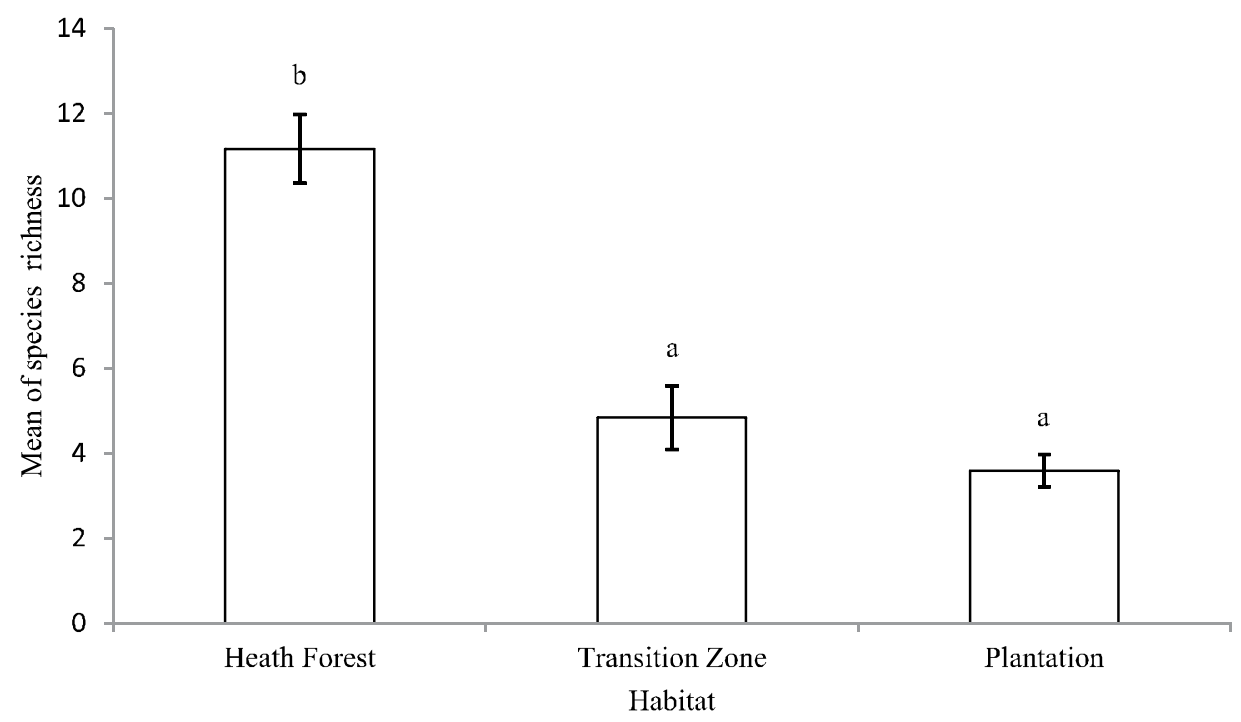

Figure 3 D ifferences in mean species richness $( \pm$ SE) of seeds extracted from soil samples collected in plots from the three habitats: Heath Forest (HF), Transition Z one (TZ) and Plantation (P). D ifferent letters above the bars indicate a significant difference (at $\alpha=0.05$ ) in the mean species richness between the two compared habitats

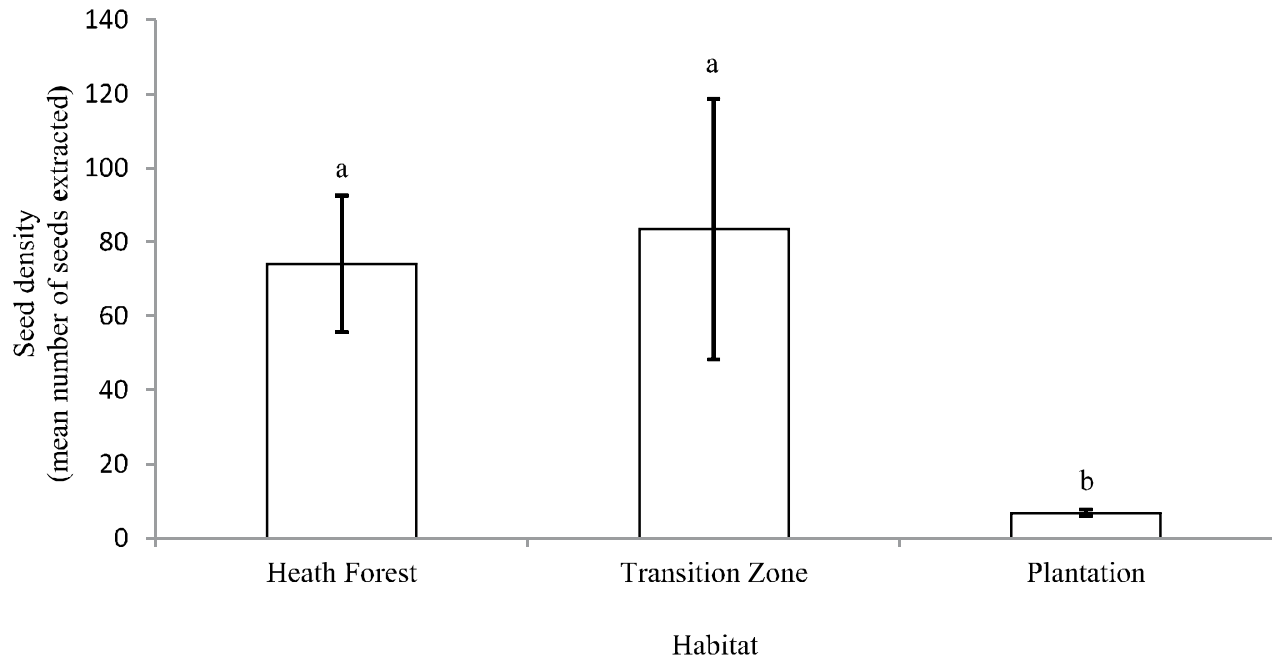

Figure 4 Differences in seed density, defined as the mean number of seeds extracted from soil samples $( \pm \mathrm{SE})$ collected in plots from the three habitats: Heath Forest (HF), Transition Zone (TZ) and Plantation (P). Different letters above the bars indicate a significant difference (at $\alpha=0.05$ ) in the mean number of seeds extracted between the two compared habitats

Seed density was significantly the highest in soil samples from TZ plots and the lowest in soil samples from $P$ plots (83.50 vs. 6.83; $F=$ 15.54, $\mathrm{p}<0.001$; Fig. 4). There was no significant difference $(F=15.54, p>0.05)$ in seed density of $\mathrm{HF}$ and TZ plots. Mean number of viable seeds was highest for HF plots, and lowest for P (46.0 vs. 2.5; $\mathrm{F}=22.79, \quad \mathrm{p}<0.001$; Fig. 5). There was no significant difference $(F=22.79, p>0.05)$ between the HF and TZ plots seed viability.
E xotic species are known to significantly reduce seed density in the soil seed banks of areas in which they establish and invade, and over time, further decrease in seed densities are typical (Bossuyt \& Hermy 2003; Gioria \& al. 2014). Thus, the conversion of parts of the Andulau tropical heath forest to an exotic A. mangum plantation for commercial purposes have resulted in a subsequent decrease in native seed density in the soil seed bank of the plantation and its immediate surroundings. 


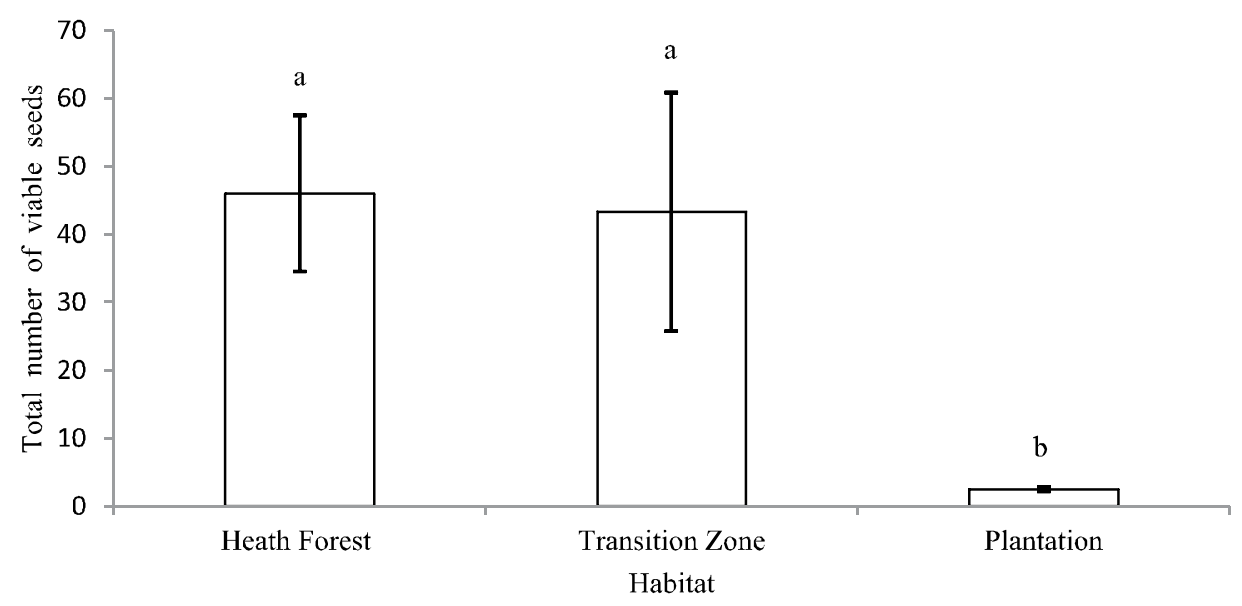

Figure 5 Differences in seed viability, defined as the mean number of viable seeds extracted $( \pm$ SE) from soil samples collected in plots from the three habitats: Heath Forest (HF), Transition Zone (TZ) and Plantation (P). Different letters above the bars indicate a significant difference (at $\alpha=0.05$ ) in the mean number of viable seeds between the two compared habitats

The highest seed viability was detected within soils sampled from the heath forest and the transition zone, and the lowest was in the plantation plots. This may partly be due to the lower seed density from plantation plots, compared to the heath forest and plots in the transition zone. However, differences in seed viability in the soil seed banks among the different habitats may also indicate varying abilities of these habitats to recover after severe disturbance events (Ashton $\notin$ al. 1998; G hebrehiwot $\&$ al. 2012). The proportion of viable seeds present in the soil seed bank at the time of disturbance is important in determining initial floristic composition following a disturbance (Hopkins \& Graham 1984). The appearance of early successional species after a disturbance event is related to the presence of viable seeds often long buried at the site (Livingston \& Allesio 1968; Luzuriaga \&al. 2005). It is, therefore, suggested that if the study area was to experience severe disturbances, the heath forest would potentially be better equipped to recover through natural regeneration, than the A. mangumplantation.

\section{Spread of Acacia mangium}

A. mangumseeds were not observed in any of the plots within the heath forest habitat about 120 $m$ away from the edge of the plantation. However, A. mangumseeds were found in one of the plots within the transition zone between these two contrasting habitats. O ur own observation within the study site in Andulau FR was of extensive spread of A. manguminto the open, disturbed areas immediately surrounding the Acada plantation itself, thus indicating A. mangumhas indeed escaped from the original plantation site. However, several factors may have allowed the adjacent intact heath forest to be protected from the A. mangumspread. Invasive alien plant species may not be able to successfully establish in intact tropical forests due to light inhibition on the ground from the closed canopy and a thick litter layer with a low proportion of bare soil (Pauchard \& Alaback 2004). Canopy coverage in particular may be crucial in slowing down the spread of invasive A. mangumseeds into the heath forest as A cacias are shade-intolerant plants (Martin \& al. 2008). Low light availability, therefore, may limit the establishment of these shade-intolerant alien invasive species in a tropical rainforest, possibly conferring some resistance to intact forests from Acadainvasions (Fine 2002; O sunkoya eal. 2005).

This current study was preliminary investigation and exploratory that it only investigated seedling emergence potentials and seed bank compositions of an intact Acada plantation, an adjacent heath forest and the transition zone between these two contrasting habitats. However, the results of this study were an important first step towards understanding the potential of invasive A cacias and their spread into the soil seed bank of an adjoining rare and vulnerable heath forest habitat in Brunei. It is suggested that an important next step would be to conduct a comprehensive survey on soil seed bank composition, seed viability, seedling 
emergence patterns of all other natural habitats vulnerable to Acada invasion in Brunei D arussalam. A comparison of these factors and the composition of standing vegetation would provide a clear insight on the invasiveness of exotic Acacias in Brunei D arussalam.

\section{CONCLUSIONS}

Comparisons of the soil seed banks between an A. mangumplantation and the adjacent heath forest have shown higher seed density, viability and species richness in the heath forest than in the A. mangumplantation. Heath forests may have a higher chance of natural regeneration following future disturbance events due to their richer soil seed banks. Clearing of intact forest for Acaia plantations has a detrimental effect on seed bank diversity and composition, which can have negative knock-on effects on native plant regeneration. Though $\mathrm{A}$. mangum is a known invasive species, due to its shade intolerant nature, it appears to have some difficulty of spreading into intact tropical forests. It is, therefore, recommended close monitoring of escaping Acaaaseedlings from the intact parent plantations to mitigate further spread of A cacias into natural habitats.

\section{ACKN OWLEDGEMENTS}

The authors thank the Forestry Department, Ministry of Primary Resources and Tourism, Brunei Darussalam for granting permission and entry permit to work in the Andulau Forest Reserve. We were grateful to Haji Ryni Haji Sofian, Mr Alex Cheng and staff from the Plantation Section of the Forestry Department for advice and assistance with site selection. We thank two anonymous reviewers for comments that have improved the manuscript. Funding for this study was provided by the Universiti Brunei D arussalam Research Grant: UBD/PNC2/ 2/ RG/ 1(204).

\section{REFERENCES}

Ashton PMS, Harris PG, Thadani R. 1998. Soil seed bank dynamics in relation to topographic position of a mixed-deciduous forest in southern New England, USA. Forest Ecol Manag 111:15-22.

Auld TD. 1986. Population dynamics of the shrub Acaaa suavedens (Sm.) Willd.: fire and the transition to seedlings. AustJ E col 11:373-85.

Ball DA, Miller SD. 1989. A comparison of techniques for estimation of arable soil seed banks and their relationship to weed flora. Weed Res 29: 36573.

Barcenas-Moreno G, Gomez-Brandon M, Rousk J, Baath E. 2009. Adaptation of soil microbial communities to temperature: comparison of fungi and bacteria in a laboratory experiment. Glob Chang Biol 15: 295057.

Baskin CC, Baskin JM. 2014. Seets Ecdogy, Biogeogady, and Evdution of DomanyandGemination $2^{\text {nd }}$ Edition San Diego (US): Academic Press.

Bossuyt B, Hermy M. 2003. The potential of soil seed banks in the ecological restoration of grassland and heathland communities. BelgJ Bot 136(1): 23-34.

Carruthers J, Robin L, Hattingh JP, Kull CA, Rangan H, Wilgen BWV. 2011. A native at home and abroad: the history politics, ethics and aesthetics of Acacias. Divers Distrib 17: 810-21.

Colautti RI, Grigorovich IA, MacIsaac HJ. 2006. Propagule pressure: anull model for biological invasions. Biol Invasions 8: 1023-37.

Cordell S, Cabin RJ, Hadway LJ. 2002. Physiological ecology of native and alien dry forest shrubs in Hawaii. Biol Invasions 4(4): 387-96.

Corlett RT. 2010. Invasive aliens on tropical East Asian islands. Biodivers Conserv 19:411-23.

Crist TO, Friese CF. 1993. The impacts of fungi on soil seeds: implications for plants and granivores in a semiarid shrub-steppe. E cology 74(8):2231-9.

D alling JW, D enslow JS. 1998. Soil seed bank composition along a forest chronosequence in seasonally moist tropical forest, Panama.J Veg Sci 9(5): 669-78.

D arbar SR, Lakzian A. 2007. Evaluation of chemical and biological consequence of soil sterilization methods. Caspian J Environ Sci 5(2): 87-91.

Davies KW, Sheley RL. 2007. A conceptual framework for preventing the spatial dispersal of invasive plants. Weed Sci 55(2): 178-84.

De Vogel EF. 1980. Seeding of Dicatyledns Structure, Dexdqpmet, Types Desciptions of 150 woody Malesian taxa Wageningen (NL): Centre for Agricultural Publishing and D ocumentation.

Din H, Metali F, Sukri RS. 2015. Tree diversity and community composition of the Tutong white sands, Brunei Darussalam: A rare tropical heath forest ecosystem.IntJ Ecol (2015): 1- 10.

Dixon KW, RocheS, Pate JS. 1995. The promotive effect of smoke derived from burnt native vegetation seed 
germination of western Australian plants. O ecologia 101:185-92.

Evans J, Turnbull J. 2004. Plantation Forestry in theTropics $3^{\text {rc }}$ Edition Oxford (UK): Oxford University Press.

Fine PVA. 2002. The invisibility of tropical forest by exotic plants.J Trop Ecol 18: 687-705.

Fujii K. 2014. Soil acidification and adaptations of plants and microorganisms in Bornean tropical forests. Ecol Res 29:371-81.

G hebrehiwot HM, Kulkarni MG, Kirkman KP, Staden J van. 2012. Smoke and heat: influence on seedling emergence from the germinable soil seed bank of mesic grassland in South Africa. Plant G rowth Regul 66:119-27.

Gibson MR, Richardson D M, Marchante E, Marchante H, RodgerJG, Stone GN. 2011. Reproductive biology of Australian Acacias: important mediator of invasiveness. Divers Distrib 17(5): 911-33.

Gioria M, Osborne B. 2010. Similarities in the impact of three large invasive plant species on soil seed bank communities. Biol Invasions 12: 1671-83.

Gioria M, Pysek P, Moravcova L. 2012. Soil seed banks in plant invasions: promoting species invasiveness and long-term impact on plant community dynamics. Preslia 84: 327-50.

Gioria M, Jarosik V, Pysek P. 2014. Impact of invasions by alien plants on soil seed bank communities: emerging patterns. Perspect Plant Ecol Evol Syst 16(3): 13242.

Hanley ME, Fenner M. 1998. Pre-germination temperature and the survivorship and onward growth of Mediterranean fire-following plant species. Acta Oecol19(2): 181-7.

Holmes PM, Cowling RM. 1997. D iversity, composition and guild structure relationships between soil-stored seed banks and mature vegetation in alien plantinvaded South African fynbos shrub lands. Plant Ecol 133(1):107-22.

Hopkins MS, Graham AW. 1984. Viable soil seed banks in disturbed lowland tropical rainforest sites in North Q ueensland. Aust J Ecol9(2): 71-9.

Ismail NAN, Metali F. 2014. Allelopathic effects of invasive Acadamangumon germination and growth of local paddy varieties. J Agron 13(4): 158-68.

Khurana E, Singh JS. 2006. Impact of life-history traits on response of seedlings of five tree species of tropical dryforest to shade.J Trop Ecol 22:653-61.

Kulkarni MG, Sparg SG, Staden J van. 2007. Germination and post-germination response of Acada seeds to smoke water and butenolide, a smoke-derived compound.J Arid Environ 69(1):177-87.

Le Maitre D C, G aertner M, Marchante E, Ens EJ, Holmes PM, Pauchard A, O'Farrell PJ, Rogers AM, Blanchard R, Blignaut J, Richardson DM. 2011. Impacts of invasive Australian Acacias: implications for management and restoration. D ivers D istrib 17: 1015-29.

Livingston RB, Allessio ML. 1968. Buried viable seed in successional field and forest stands, Harvard forest, Massachusetts. B Torrey Bot Club 95(1): 58-69.

Lockwood JL, Cassey P, Blackburn T. 2005. The role of propagule pressure in explaining species invasions. TrendsEcolEvol 20(5):223-8.

Luzuriaga AL, Escudero A, Olano JM, Loidi J. 2005. Regenerative role of seed banks following an intense soil disturbance. Acta $O$ ecol 27: 57-66.

Martin PH, Canham CD, Marks PL. 2008. Why forests appear resistant to exotic plant invasions: intentional and introductions, stand dynamics, and the role of shade intolerance. FrontEcol Environ 7:142-9.

Metali F, Salim KA, Tennakoon KU, Burslem D FRP. 2015. Controls on foliar nutrient and aluminium concentrations in a tropical tree flora: phylogeny, soilchemistryand interactions among elements. New Phytol 205(1): 280-92.

Moran JA, Barker MG, Moran AJ, Becker P, Ross SM. 2000. A comparison of the soil water, nutrient status and litterfall characteristics of tropical heath and mixeddipterocarp forest sites in Brunei. Biotropica. 32(1): 2-13.

Neary DG, Klopatek CG, DeBano LF, Ffolliott PF. 1999. Fire effect on belowground sustainability: a review and synthesis. ForestE col Manag 122: 51-71.

$\mathrm{Ng}$ FSD. 1991. Manual of forest fruits, seeds and seedlings volume 2. Kuala Lumpur (MY):: Forest Research Institute Malaysia.

O sunkoya O O, O thman FE, Kahar RS. 2005. Growth and competition between seedlings of an invasive Acada mangum and those of a native Borneo heat-forest species, Mdastomabeccarianum E col Res 20: 205-14.

Padmanaba M, Corlett RT. 2014. Minimizing risks of invasive alien plant species in tropical production forestmanagement. Forests 5: 1982-98.

Pauchard A, Alaback PB. 2004. Influence of elevation, land use, and landscape context on patterns of alien plant invasions along roadsides in protected areas of south-central Chile. Conserv Biol 18(1): 238-48.

Portlock CC, Shea SR, Majer JD, Bell DT. 1990. Stimulation of germination of Acada puldhdla: Laboratory basis forforest management options.J Appl Ecol 27: 31924.

Price JN, Wright BR, Gross CL, Whalley WRDB. 2010. Comparison of seedling emergence and seed extraction techniques for estimating the composition of soil seed banks. Methods Ecol Evol 1: 151-7.

Proctor J. 1999. Heath forest and acid soils. Bot J Scotl 51(1):1-14.

R Core Team [Internet]. 2013. R: A language and environment for statistical computing. $R$ 
Foundation for Statistical Computing, Vienna, Austria. [cited 201504 01]; Available from: http:/ / www.R-project.org. ISBN 3-900051-07-0.

Rawson T, Davies R, Whalen M, Mackay D. 2013. Firerelated cues and germination from the soil seed bank of senescent remnants of mallee vegetation on Eastern K angaroo Island. Austral Ecol 38: 139-51.

Read TR, Bellairs SM, Mulligan DR, Lamb D. 2000. Smoke and heateffects on soil seed bank germination for the re-establishment of a native forest community in New South Wales. A ustral Ecol 25:48-57.

Richardson DM, Kluge RL. 2008. Seed banks of invasive Australian Acadaspecies in South Africa: Role in invasiveness and options for management. Perspect PlantEcol Evol Syst 10: 161-77.

Richardson DM, Rejmanek M. 2011. Trees and shrubs as invasive alien species - a global review. Divers Distrib 17: 788-809.

Simberloff D. 2009. We can eliminate invasions or live with them successful management projects. Biol Invasions 11(1): 149-57.

Swaine MD, Whitmore TC. 1988. On the definition of ecological species groups in tropical rainforest. Vegetatio 75: 81-6.

Vilà M, Espinar JL, Hejda M, Hulme PE, Jarosik V, Maron JL, et al. 2011. Ecological invasion of invasive alien plants: a meta-analysis of their effects on species, communities and ecosystems. Ecol Lett 14(7): 702-8.

Wagner M, Mitschunas N. 2008. Fungal effects on seed bank persistence and potential applications in weed biocontrol: areview. Basic Appl Ecol 9: 191-203.

Wang J, Ren H, Yang L, Li D, Guo Q. 2009. Soil seed banks in four 22-year-old plantations in South China: Implications for restoration. For Ecol Manage 258: 2000-6.

Wahid A, Gelani S, Ashraf M, Foolad, MR. 2007. Heat tolerance in plants: an overview. Environ Exp Bot 61:199-223.

Willis TJ, Read J. 2002. Effects of heat and smoke on germination of soil-stored seed in a south-eastern Australian sand heathland. Aust J Bot 50(2): 197206.

Wong KM, Ahmad JA, Low YW, Kalat MAA. 2015. Rainforest Plants and Flowers of Buni Danussalam Bandar Seri Begawan (BN): Forestry D epartment, Ministry of Industry and Primary Resources.

Wong KM, Kamariah AS. 1999. Forest and Trees of Bruni Danussalam Bandar Seri Begawan (BN): Universiti BruneiD arussalam.

Zuloaga-Aguilar S, Briones O, Orozco-Segovia A. 2011. Seed germination of montane forest species in response to ash, smoke and heat shock in Mexico. Acta O ecol 37: 256-62. 